\title{
Validation of the children's hope scale amongst a sample of adolescents in the Western Cape Region of South Africa
}

\author{
Shazly Savahl, Ferran Casas and Sabirah Adams
}

\begin{abstract}
A growing body of research has provided evidence for the cognitive-motivational construct of hope as a psychological strength, particularly for adolescents confronted with ensuing adverse conditions. Given the dearth of research on hope in South Africa, the aim of the current study was to validate Snyder's Children's Hope Scale within this context. A cross sectional survey design was used to collect data from a sample of 1022 adolescents between the ages of 13 and 16 (449 males and 573 females) attending high schools within the Western Cape geographical region of South Africa. The sample was selected using a two-stage stratified random sampling protocol, with socio-economic status (low, medium and high) as the defining variable. Data were collected using Snyder's (1997) Children's Hope Scale which was adapted to the South African context and translated into Afrikaans. Confirmatory factor analysis was used to analyse the data. The results indicate good fit indices for the overall model with two error co-variances $\left(x^{2}=35.692 ; d f=7 ; p=0.00 ; \mathrm{CFI}=0.984 ; \mathrm{RMSEA}=0.063\right.$; $\left.\mathrm{SRMR}=0.023\right)$. Multigroup analysis with constrained factor loadings and intercepts show good fit across socioeconomic status groups which indicate that these groups can be compared by correlations, regressions and means. The overall findings suggest that the Children's Hope Scale is an appropriate measure for use in the South African context.
\end{abstract}

\section{Background}

A growing body of research has provided evidence for the cognitive-motivational construct of hope as a psychological strength, particularly for adolescents confronted with ensuing adverse conditions (Valle et al. 2006). As far back as 1963, the renowned psychologist of religion and clinical psychology, Pruyser (1963) identified a dearth in scholarly theorisation and literature on the construct of hope. This was met with a burgeoning increase in accounts and understandings of hope, notably in theological studies, pastoral literature, as well as in psychology (Pruyser, Frank, and Stotland); what Kwan (2010) refers to as the BPsychologies of hope ${ }^{\wedge}$. Further empirical and theoretical initiatives to address the gaps in the literature, through for example, the development of the Hopelessness Scale for Children (see Kazdin et al. 1986), placed emphasis on negative expectancies of the self and the future. The 21st century has since seen a shift and proclivity in the conceptualisation and identification of positive psychological constructs which cultivate healthy development encompassed in the discipline of positive psychology (see Seligman and Csikszentmihalyi 
2000). This shift resulted in a number of theorisations of the essence and meaning of hope in general, and in particular on children's hope. Snyder's theory on children's hope has been one of the most influential in the field and incorporates three core components of hope as a construct namely goals, agency and pathways (Snyder et al. 1991). The theory further preferences two distinct, yet interrelated, types of hope cognitions within an individual identified as pathways described as Bworkable routes to goals ${ }^{\wedge}$; and agency described as Bself-related beliefs about initiating and sustaining movement toward those goals ${ }^{\wedge}$ (Snyder et al. 1991, p. 401).

Whilst the constructs of hope and optimism incorporate the expectation that a goal can be attained, hope specifically incorporates the fortitude to attain and accomplish one's goals. Additionally, despite the inclination to aggregate the constructs of hope and optimism, a metaanalytic review conducted by Alarcon et al. (2013) focusing on hope and optimism found that the two are distinct constructs - both associated with specific indices of psychological and physical well-being. A number of studies in fact show that hope is a better predictor of psychological well-being in comparison to optimism (Bryant and Cvengros 2004; Holleran and Snyder 1990). It has therefore become crucial to identify and understand how children think about, reflect upon, and plan to attain their goals which in turn determines how they cope with stressors and unintended negative outcomes in their lives (Snyder et al. 1997). Recent research has shown children's hope to be inextricably linked to their overall wellbeing (see Gilman et al. 2006; Merkaš and Brajša-Žganec 2011; Savahl et al. 2013; Snyder et al. 2005; Snyder et al. 2003). Subsequently, a deeper understanding of children's hope is of considerable importance, specifically in the South African context which has as a key policy mandate, the improvement of children's lives and well-being.

Notwithstanding the shift in the conceptualisation of hope as a positive indicator of well-being, researchers note that cognisance be taken of the possible negative aspect of hopeful or positive expectations (McNulty and Fincham 2012). McNulty and Fincham (2012) caution that exceedingly high levels of hope could result in negative outcomes, particularly those forms that are not based in reality. The distinction between robust and naive hope is important in this regard. Robust versions of hope are Brooted in a sense of reality^ (Singh and Sawyer 2008, p.4), founded on the achievement of attainable goals by emphasising human agency, resilience, and sustainability (Sawyer et al. 2007); whilst naive hope is characterised by unrealistic optimism and a lack of understanding of the nature of the obstacles that could inhibit the attainment of goals (Sawyer et al. 2007; Singh and Sawyer 2008).

Given the significant relationship between hope and well-being amongst children and adolescents, further empirical investigations are required to unpack the dynamics and nature of the relationship. Key to this understanding is identifying and examining factors that could influence this relationship. Within developing economies, Socio-Economic Status (SES) has emerged as a critical factor. While there is considerable variability in SES across countries, it remains a significant indicator of children's well-being (Bradley and Corwyn 2002). Although there is currently no consensus as to the components of SES, many researchers adopt the definition proposed by Coleman (1988) of capital comprised of three components, namely 
financial capital (referring to material resources), human capital (non -material resources such as education), and social capital (resources achieved through social relationships) (Krieger et al. 1997). Research has found that SES is related to children and adolescents' health, cognitive and educational attainment, socio-emotional development, and access to resources (Bradley and Corwyn 2002). Economic factors such as Gross Domestic Product lower levels of household income and recent decreases in income were linked to decreased average levels of subjective well-being among children (Bradshaw and Richardson 2009; Bradshaw et al. 2011; Rees et al. 2011). An important consideration and indicator of inequality in a country is the Gini Co-effficient ${ }^{1}$, which is the Binternational standard for measuring the distribution (or dispersion) of income and wealth in a country ${ }^{\wedge}$, and measured by a ratio between $O$ and 1 ('o' indicating that all individuals receive the same income and ' 1 ' indicating that only one individual receives all the income). It is also referred to as the Gini Index (Benson, 1970, as cited in Bosch et al. 2010).

Notwithstanding the fundamental premise of equality in the South African Constitution, inequality remains pervasive in the country. With a Gini Index of 0.63 (Bosch, et al. 2010; Stats 2008), considered to be one of the highest in the world (in terms of wealth and income), it demonstrates a great dispersion of both wealth and income between the privileged and the disadvantaged. Although this inequality is experienced by the majority of the population, the burdens of these Bmultiple overlapping layers of inequality ${ }^{\wedge}$ are often endured by children who necessitate care and supervision from adults for both safety and basic tenets of their well-being (Hall et al. 2012, p. 24). An exploration of the impact of SES and social inequality on well-being is incomplete without reference to the oppressive backdrop of Apartheid. Based on a philosophy of segregation and exclusion the Apartheid legislative framework characterised the socio-political landscape of South Africa for nearly five decades. Characterised by institutionalised racism, systematic oppression and domination of one group over another, Apartheid resulted in a significant proportion of the population being disenfranchised, denied access to resources, land, education opportunities and basic human rights.

One of the most devastating legacies of Apartheid is the extreme levels of social inequality experienced by various cohorts of the population. This has manifested in the polarisation of communities and neighbourhoods into privileged or high SES and disadvantaged or low SES. Privileged communities are characterised by high income, high educational attainment, high levels of employment, and low incidence of violence. Disadvantaged communities are characterised by low educational attainment and income, high rates of substance abuse, unemployment, crime and violence. Located between the high and low extremes a cohort presenting with a medium socio-economic status is emerging. This population cohort mainly consists of individuals that have managed intergroup mobility since the attainment of democracy in 1994. Typically this cohort is characterised as the emerging middle class and

\footnotetext{
1 The Gini Index is calculated using a Lorenz curve which plots the cumulative percentages of total income received against the cumulative number of recipients, beginning with the poorest individual or household. The Gini index measures the area between the Lorenz curve and a hypothetical line of absolute equality, expressed as a percentage of the maximum area under the line. Thus a Gini index of 0 represents perfect equality, while an index of 100 implies perfect inequality.
} 
consists of previously disadvantaged individuals who through education, resilience and other positive psychological traits managed to achieve a reasonable level of economic security.

While the past few decades have shown a substantial increase in empirical initiatives on children's well-being, there are fewer studies on the theoretical and conceptual configurations of hope. Isaacs and Savahl (2014) have specifically identified the need for further considerations of hope among children and adolescents in South Africa. While exploratory investigations are required, validation of scales that measure hope amongst children and adolescents in local contexts are critical. Of the existing scales, Snyder et al (1997) Children's Hope Scale is the most widely used and has shown good psychometric properties across a range of contexts. This study hopes to further contribute in this regard by testing and validating the Children's Hope Scale amongst a sample of adolescents in the Western Cape of South Africa.

\section{Aims and Objectives}

The overall aim of the study is to validate the Children's Hope Scale amongst a sample of adolescents from the Western Cape region of South Africa. The following objectives guide the study:

To test the overall fit structure of the Children's Hope Scale

To test the fit indices of the Children's Hope Scale by socio-economic status group

(low, medium, high)

\section{Method}

\subsection{Research Design}

The study followed a cross-sectional survey design with Confirmatory Factor Analysis used to test the fit indices of the scale.

\subsection{Sampling}

Due to the pervasiveness of social inequality in the population, a sampling frame consisting of both privileged and disadvantaged communities was established consisting of participants attending high schools within the Western Cape Education Department (WCED) Metropole school system. A two-stage stratified random sampling protocol was used to ensure that children from various socio-economic status groups were selected. In the first stage schools were stratified according to their location within specific Education Management District Councils (EMDC's). Thereafter, schools were randomly selected within each of these EMDC's using socio-economic status as the defining variables. It was envisaged to obtain an equal number of participants from low, medium and high socioeconomic status groups. Once the schools were selected, two classes from each grade were selected to participate. Where the school was dual language medium, one English and Afrikaans class each was selected. A total of 1096 adolescents between the ages of 13 and 16 years participated in the study. After damaged and incomplete questionnaires were assessed and discarded, the data were cleaned and missing values replaced using regression. The final sample consisted of 1022 participants. Of these $55.2 \%$ were from the low SES, 32.1 
$\%$ from the medium and $12.7 \%$ from the high SES group. Girls comprised $56.1 \%$ whilst boys comprised $43.9 \%$ of the sample.

\subsection{Instrumentation}

Data were collected using Snyder et al. (1997) Children's Hope Scale (CHS). The CHS is based on Snyder's theory of hope and measures goal orientated hopeful thinking through a sixitem self-report scale, with response options ranging from one (None of the time) to six (All of the time). The scale was initially validated as a cohesive two factor structure measuring agency (items 1, 3 and 5) and pathways (items 2, 4 and 6). While a two factor model was supported in subsequent validation studies (see Pulido-Martos et al. 2014; Valle et al. 2004) others found better fit for a one-dimensional (mono-factorial) structure (see Bickman et al. 2010; Dew-Reeves et al. 2012). While it is recommended that the scale be scored as the mean total of the six items, no cut-scores were recommended by the original scale authors. Cluster analysis conducted by Gilman et al. (2006) identified clusters of low, average and high hope, while Merkaš and Brajša-Žganec (2011) identified clusters of low and high hope. Furthermore, Bickman et al. (2010) proposed cut-scores of low, medium and high hope categories (see Table 1).

The CHS produces acceptable psychometric properties. Internal consistency of the scale showed co-efficient alphas of 0.83 and 0.84 ; with item-total correlations ranging from 0.51 to 0.69 and 0.55 to 0.68 (Valle et al. 2004). Snyder et al. (1997) also reported acceptable 1 month test-retest reliability between 0.71 and 0.73 .

For the purposes of the current study Snyder et al (1997) original scale was adapted to the South African context. This process included the cognitive testing, translation into Afrikaans and piloting of the measure.

Table 1 Proposed cut scores (Bickman et al. 2010)

\begin{tabular}{lll}
\hline Low & Medium & High \\
\hline$<3.0$ & $3.0-4.67$ & $>4.67$ \\
\hline
\end{tabular}

The cognitive testing process involved two focus groups with 10 adolescents each. The participants of the focus groups were purposively selected from schools within the sampling frame. The responses of the participants of the focus groups assisted in the phrasing, refining and modification of items on the scale. Thereafter, the revised instrument was translated into Afrikaans using the backward translation method using two independent Afrikaans translators. Following the translation, both questionnaires (English and Afrikaans) were piloted with a sample of 150 adolescents, randomly selected from schools located in low, medium and high SES communities. This process focused on gathering information relating to how the participants responded to the measure - the wording of the items and the nuances 
related to the translation of the items. Information gathered during the pilot was used to revise and finalise the measure.

\subsection{Procedure and Ethics}

Once the schools were selected, the research team met with the principals and life skills teachers. An information session was arranged with participants from the selected classes where the aim, the nature of their involvement and ethics of the study were discussed. More specifically they were advised on the ethics principles of anonymity, privacy and the right to withdraw. Those who agreed to participate were requested to provide signed consent as well as obtain signed consent from their parents. Only those who returned the consent forms participated in the study. The instrument was researcher administered during an administration period at the beginning of the school day. The average time of completion was approximately $15 \mathrm{~min}$.

\subsection{Data Analysis}

The fit indices of the Children's Hope Scale was tested by means of confirmatory factor analysis (CFA) using AMOS version 22 to ascertain the appropriateness of using the scale in a South African context with diverse groups.

Following recommendations from Casas et al. (2012), all participants with more than two missing values were deleted and missing values substituted by regression. Maximum likelihood estimation was used with kurtosis and departures from normality attended to using the bootstrap method (500 samples). Chi Square, CFI (comparative fix index), RMSEA (root mean square error of approximation) and SRMR (standardized root mean square residual) were used as fit indexes. Lower Chi Square scores indicate a better fit, while scores higher than 0.950 were accepted for CFI and scores below 0.05 were regarded as a good fit for RMSEA and SRMR.

To compare CFA scores between groups factor invariance was considered. Factor invariance refers to the degree that items in a scale have the same meaning for members of different groups and is a prerequisite for factor comparison. If it is not observed, means or correlation coefficients may be attributed to real distribution differences or to different meanings of the variables (Meredith 1993). Two kinds of factor invariance were considered. Firstly, metric factor invariance which is a requisite for comparing variances, covariance or regression coefficients and secondly, scalar factor invariance which is a requisite for comparing means between groups (Casas et al. 2012). Subsequently, multi-group models were tested in three steps. In the first step, the multi-group model fit with no constraints was tested. In the second step, factor invariance was tested with constrained standardized factor loadings. And finally, factor invariance by constraining the intercepts of the equation was tested. 


\section{Results}

\subsection{Descriptive Statistics}

Skewness of the items ranged from -0.290 to -0.523 with Kurtosis from -560 to -1.020 . These departures from normality were attended to using the Bootstrap method (500 samples) in Amos. Cronbach Alpha for the overall scale was an acceptable 0.820 which is consistent with other validation studies. Item mean scores ranged from 3.82 for the low SES group on Item 5 to 4.56 for the medium SES group on Item 2. The item mean scores are presented in Table 2.

Overall mean scores ranged from 3.96 for the low SES group to 4.42 for the medium SES group (see Table 3). The mean of the total score was 24.89, which is comparable to means reported by the scale authors across diverse samples (see Snyder et al. 1997). Means analysis (one way ANOVA) showed significant differences between SES groups $(f=21.16 ; p<0.0001)$; whilst Levene's test showed significant differences in score dispersion between the low and medium SES group and between the low and high SES group.

\subsection{Confirmatory Factor Analysis}

Confirmatory factor analysis was used to test the fit statistics of the overall model and multigroup model by SES group. Initial tests to fit a two factor model as suggested by the original scale theory (see Snyder et al. 1997) showed an unacceptably high correlation (>0.9) between the two factors which calls into question a two factor model.

Table 2 Item mean scores by SES and overall pooled sample

\begin{tabular}{|c|c|c|c|c|c|c|c|c|}
\hline & \multicolumn{2}{|c|}{ Low SES } & \multicolumn{2}{|c|}{$\begin{array}{l}\text { Medium } \\
\text { SES }\end{array}$} & \multicolumn{2}{|c|}{ High SES } & \multicolumn{2}{|c|}{ Overall } \\
\hline & Mean & SD & Mean & SD & Mean & SD & Mean & SD \\
\hline Hope 1: I think I am doing well & 4.02 & 0.93 & 4.40 & 1.25 & 4.28 & 1.42 & 4.18 & 1.32 \\
\hline $\begin{array}{l}\text { Hope } 2 \text { : I can think of many ways to get the things } \\
\text { in life that are most important to me }\end{array}$ & 4.11 & 1.09 & 4.56 & 1.27 & 4.39 & 1.46 & 4.29 & 1.37 \\
\hline $\begin{array}{l}\text { Hope } 3 \text { : I am doing just as well as other adolescents } \\
\text { my age }\end{array}$ & 3.93 & 1.18 & 4.48 & 1.28 & 4.35 & 1.56 & 4.16 & 1.45 \\
\hline $\begin{array}{l}\text { Hope } 4 \text { : When I have a problem, I can come up with } \\
\text { many ways to solve it }\end{array}$ & 3.90 & 1.32 & 4.20 & 1.46 & 4.05 & 1.57 & 4.02 & 1.51 \\
\hline $\begin{array}{l}\text { Hope } 5 \text { : I think the things I have done in the past will } \\
\text { help me in the future }\end{array}$ & 3.82 & 1.25 & 4.41 & 1.51 & 4.33 & 1.64 & 4.07 & 1.58 \\
\hline $\begin{array}{l}\text { Hope 6: Even when others want to quit, I know I can } \\
\text { find many ways to solve the problem }\end{array}$ & 4.00 & 1.27 & 4.47 & 1.33 & 4.15 & 1.54 & 4.17 & 1.46 \\
\hline
\end{tabular}


Table 3 Overall mean scores SES group

\begin{tabular}{lcc}
\hline SES & Mean & SD \\
\hline Low SES & 3.96 & 1.11 \\
Medium SES & 4.42 & 0.96 \\
High SES & 4.26 & 0.87 \\
Overall Item Mean & 4.15 & 1.05 \\
Total Score & 24.89 & 6.31 \\
\hline
\end{tabular}

However, similar to findings by (Bickman et al. 2010) the results of the current study suggest a good fit for a single factor model. This means that the scale is a satisfactory measure of the single higher order construct of hope. Figure 1 presents the overall model which shows a good fit with two error co-variances (Hope 1 - Hope 3; Hope 4 - Hope 6).

Table 4 presents the standardised factor loadings for the overall model and SES groups. Standardised estimates show adequate loadings for all items on the overall model as well as across SES groups. These loadings suggest adequate contributions to the higher order construct of hope by both agency (Hope 1, 3, 5) and pathways (Hope 2, 4, 6).

As previously indicated, to compare coefficients across SES groups, metric factor invariance was tested using three steps. In the first step metric factor invariance was tested with an unconstrained multi-group model (Model 3). In the second step standardised factor loadings were constrained across SES groups (Model 4). Metric factor invariance is tenable if the fit of the constrained model is not significantly worse (0.01) than the fit of the unconstrained model (Brannick 1995; Cheung and Rensvold 2002). Finally, intercepts were constrained (Model 5). The fit statistics for the various models are presented in Table 5. 


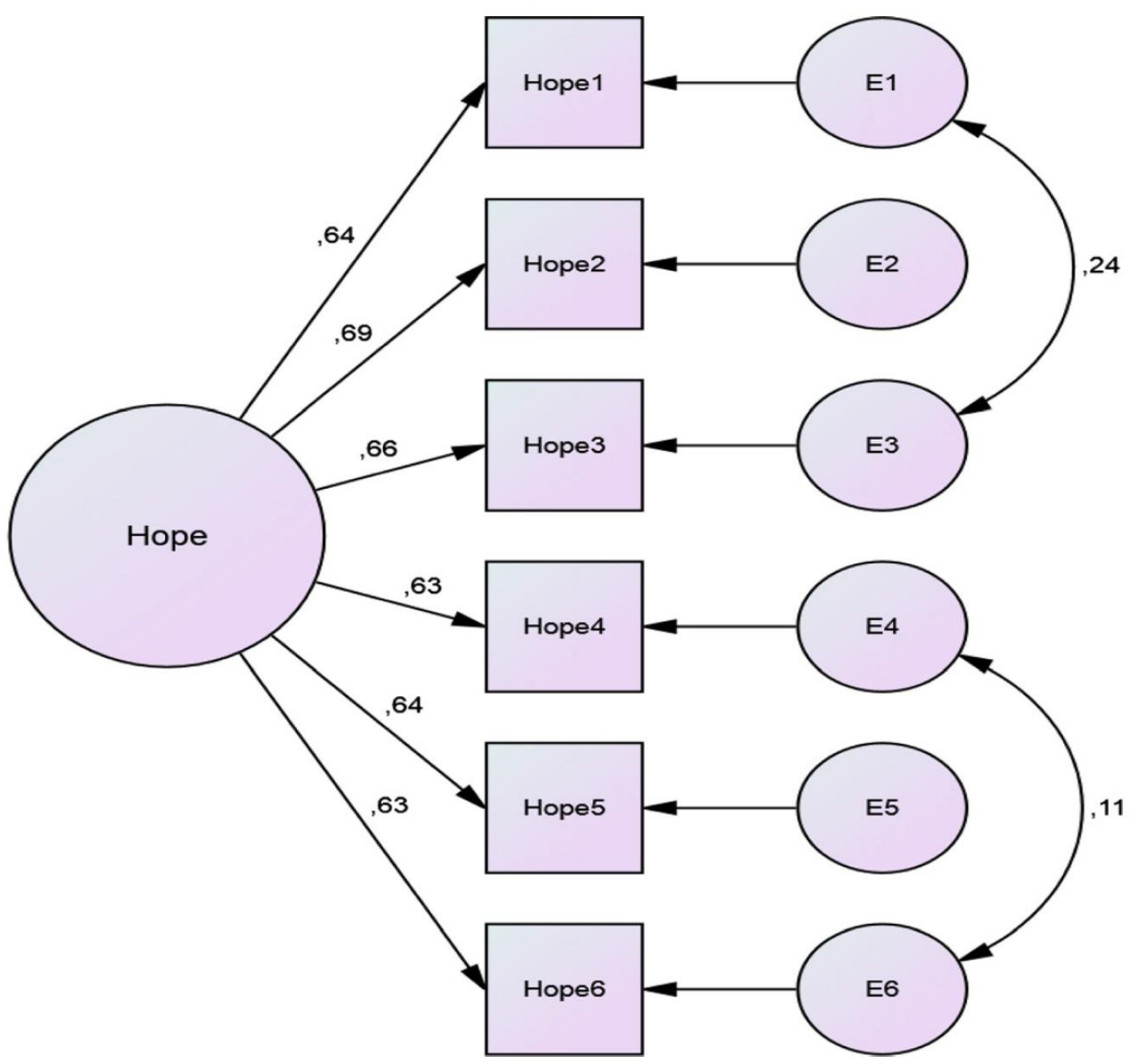

Fig. 1 Overall model

Table 4 Standardised regression weights for items on the CHS

Bootstrap ML, $95 \%$ confidence intervals.

\begin{tabular}{|c|c|c|c|c|c|c|}
\hline \multicolumn{3}{|c|}{ Resamples $=500$} & \multirow[t]{2}{*}{ Estimate } & \multirow[t]{2}{*}{ Lower } & \multirow[t]{2}{*}{ Upper } & \multirow[t]{2}{*}{ Sig. } \\
\hline Overall & & & & & & \\
\hline Hope 1 & $\leftarrow$ & Hope & 0.64 & 0.58 & 0.69 & $<0.05$ \\
\hline Hope 2 & $\leftarrow$ & Hope & 0.69 & 0.64 & 0.74 & $<0.05$ \\
\hline Hope 3 & $\leftarrow$ & Hope & 0.66 & 0.61 & 0.71 & $<0.05$ \\
\hline Hope 4 & $\leftarrow$ & Hope & 0.63 & 0.58 & 0.68 & $<0.05$ \\
\hline Hope 5 & $\leftarrow$ & Hope & 0.64 & 0.59 & 0.69 & $<0.05$ \\
\hline Hope 6 & $\leftarrow$ & Hope & 0.63 & 0.58 & 0.68 & $<0.05$ \\
\hline
\end{tabular}


The initial model (Model 1) showed a good fit structure which improved with two error covariances (Model 2). For the multi-group model good fit structure was obtained with both constrained factor loadings (Model 4) and intercepts (Model 5). This means that the multigroup model is a good fit across SES groups; therefore the groups can be compared by correlations, regressions and means. The standardised factor loadings and the significant mean differences are presented in Table 6 below.

\section{Discussion}

Given the high level of social inequality and disparities between the rich and poor in South Africa it is paramount to consider the diversity of life experiences between various groups. Largely aligned to the socio-political history of the country, growing up in South African societies as a child and adolescent is one of diversity of experience, characterised by the polarised 'lifeworld' of opportunity and provision on the one hand, and deprivation on the other. Accurately capturing these experiences and correlates of child and adolescent well-being requires careful consideration of the measures.

Table 5 Fit statistics for the overall pooled data and multi-group constrained models by SES

\begin{tabular}{|c|c|c|c|c|c|c|c|}
\hline \multicolumn{2}{|c|}{ Model } & \multirow{2}{*}{$\frac{X 2}{86.78}$} & \multirow{2}{*}{$\frac{\mathrm{df}}{9}$} & \multirow{2}{*}{$\frac{p \text {-value }}{0.00}$} & \multirow{2}{*}{$\frac{\text { CFI }}{0.957}$} & \multirow{2}{*}{$\frac{\text { RMSEA }}{0.092(0.075-0.110)}$} & \multirow{2}{*}{$\frac{\text { SRMR }}{0.036}$} \\
\hline 1 & Initial Model & & & & & & \\
\hline 2 & $\begin{array}{l}\text { Modified Model (pooled sample) } \\
\text { with } 2 \text { error co-variances }\end{array}$ & 35.69 & 7 & 0.00 & 0.098 & $0.063(0.044-0.085)$ & 0.023 \\
\hline 3 & Multi-group SES (Unconstrained) & 51.94 & 21 & 0.00 & 0.982 & $0.038(0.025-0.051)$ & 0.028 \\
\hline 4 & $\begin{array}{l}\text { Multi-group SES (Constrained Factor } \\
\text { Loadings) }\end{array}$ & 59.46 & 31 & 0.002 & 0.984 & $0.030(0.018-0.041)$ & 0.036 \\
\hline 5 & $\begin{array}{l}\text { Multi-group SES (Constrained Factor } \\
\text { Loadings \& Intercepts) }\end{array}$ & 73.58 & 41 & 0.001 & 0.982 & $0.028(0.017-0.038)$ & 0.037 \\
\hline
\end{tabular}


Table 6 Standardised factor loadings for items on the CHS by SES group

Bootstrap ML, $95 \%$ confidence

\begin{tabular}{|c|c|c|c|c|c|c|c|c|c|}
\hline \multirow[t]{2}{*}{ Resamples $=500$} & \multicolumn{3}{|l|}{ Low SES } & \multicolumn{3}{|c|}{ Medium SES } & \multicolumn{3}{|c|}{ High SES } \\
\hline & Estimate & Lower & Upper & Estimate & Lower & Upper & Estimate & Lower & Upper \\
\hline Hope $1 \leftarrow$ Hope & 0.62 & 0.56 & 0.68 & 0.62 & 0.54 & 0.70 & 0.71 & 0.62 & 0.79 \\
\hline Hope $2 \leftarrow$ Hope & 0.69 & 0.63 & 0.74 & 0.65 & 0.58 & 0.72 & 0.74 & 0.64 & 0.82 \\
\hline Hope $3 \leftarrow$ Hope & 0.65 & 0.59 & 0.70 & 0.67 & 0.59 & 0.74 & 0.67 & 0.56 & 0.76 \\
\hline Hope $4 \leftarrow$ Hope & 0.63 & 0.57 & 0.69 & 0.58 & 0.51 & 0.64 & 0.59 & 0.49 & 0.68 \\
\hline Hope $5 \leftarrow$ Hope & 0.65 & 0.59 & 0.70 & 0.60 & 0.53 & 0.68 & 0.64 & 0.55 & 0.71 \\
\hline Hope $6 \leftarrow$ Hope & 0.63 & 0.57 & 0.69 & 0.60 & 0.53 & 0.67 & 0.59 & 0.49 & 0.68 \\
\hline${ }^{*}$ CHS Mean Differences & 0 & 0 & 0 & $* * 0.50$ & 0.35 & 0.67 & $* * 0.33$ & 0.15 & 0.55 \\
\hline
\end{tabular}

* The Low SES group is used as the point of reference

** Significant differences

Notwithstanding the diversity, the CHS showed good cross-cultural adaptation across SES groups. Confirmatory Factor Analysis showed appropriate fit statistics for the overall pooled and multi-group model as well as across the various SES groups. The tenability of scalar factor invariance across SES groups suggests that the items on the scale had the same meaning across the SES groups and that these groups can be compared by correlations, regressions and means.

All the items show adequate factor loadings, between 0.63 and 0.69 with means ranging between 4.02 and 4.29. Significant mean differences were observed between SES groups. However, using Bickman et al. (2010) proposal for cut-scores, all these scores fall within the range of 'medium hope'. Surprisingly the highest mean score for the overall scale was obtained by the medium SES group (4.42). While the results indicate a significant difference between SES groups it is suggesting, at a crude level, that perhaps the opportunities afforded by membership to the 'emerging middle class' is having a positive influence on adolescents' subjective indicators of well-being. Following Snyder et al. (2002) theory this essentially means that adolescents of this SES group are both motivated and finding multiple pathways to achieve realistic goals. These adolescents are typically born post the 1994 democratic elections and are perhaps less affected by Apartheid's exclusionary practices and thus engendering a more positive outlook on life. For low SES adolescents, however, a sense of marginalisation and social exclusion, and lack of access to opportunities are, however, still stark realities. One could then speculate that it is perhaps not SES, but rather the level of social inequality that plays a critical role in levels of hope. However, the low SES group also presented with scores which showed a significantly higher level of variance than the other groups suggesting that some participants have high hope. This finding is not unusual as a 
positive bias is often found when measuring positive psychological traits, such as hope. It also resonates with findings of a qualitative study conducted by Isaacs and Savahl (2014) in a low SES community in Cape Town. They found that adolescents demonstrated high levels of robust hope which was advanced by levels of religiosity, interacting with positive role models and the importance that they attached to having hope.

Contrary to Snyder et al (1997) supposition of a two factor model for the CHS, the current study provided evidence that the CHS loads on a single factor. This finding lends support to recent validation studies which show good scale characteristics for a mono-factorial model (see Bickman et al. 2010; Dew-Reeves et al. 2012; Merkaš and Brajša-Žganec 2011). In an attempt to explain the single factor phenomenon Merkaš and Brajša-Žganec (2011) put forward a hypothesis which suggests an underlying structure of hope that is invariant across cultural, language and social groups. However, given the high correlation between pathways and agency, an alternative hypothesis suggesting that these factors are indistinguishable from one another, and that the scale could be measuring the single construct of goal orientated hopefulness should be considered. Therefore, similar to subsequent validation studies (see Pulido-Martos et al. 2014) it is recommended to use the total score of the CHS as a measurement of hope in children and adolescents.

\section{Conclusion and Recommendations}

Aligned to the advancement of the field of positive psychology and international trends in child well-being research, the importance of hope as a positive psychological strength has become well-established. Various studies have pointed to the importance of hope in children's overall quality of life and translation and validation studies amongst diverse groups have increased. This study hopes to make a further contribution in this regard. Findings point to the appropriateness of the measure for use in the South African context and amongst adolescents from various SES groups. The factorial structure has again emerged as a point of discussion with findings from the current study suggesting good fit structure for a mono-factorial model. Similar to Pulido-Martos et al. (2014) we recommend the use of a total score of the measure as means for interpretation. Beyond the need for further validation studies, research exploring the mechanisms through which hope functions is recommended. Research to determine the extent to which programmes aimed at improving goal orientated hopefulness could positively influence the overall quality of life of children and adolescents in impoverished contexts would also be useful.

\section{Acknowledgments}

The authors would herewith like to acknowledge the financial and institutional support of the National Research Foundation of South Africa. 


\section{References}

Alarcon, G. M., Bowling, N. A., \& Khazon, S. (2013). Great expectations: a meta-analytic examination of optimism and hope. Personality and Individual Differences, 54, 821827.

Bickman, L., Athay, M. M., Riemer, M., Lambert, E.W., Kelley, S. D., Breda, C., et al. (Eds.) (2010). Manual of the Peabody Treatment Progress Battery, 2nd ed. [Electronic version]. Nashville: Vanderbilt University. http://peabody.vanderbilt.edu/ptpb/.

Bosch, A., Roussouw, J., Claassens, T., \& du Plessis, B. (2010). A second look at measuring inequality in South Africa: A modified gini coefficient. School of Development Studies, Working paper (58). University of Kwazulu-Natal.

Bradley, R. H., \& Corwyn, R. F. (2002). Socioeconomic status and child development. Annual Review of Psychology, 53(1), 371-399.

Bradshaw, J., \& Richardson, D. (2009). An index of child well-being in Europe. Child Indicators Research, 2(3), 319-351.

Bradshaw, J., Keung, A., Rees, G., \& Goswami, H. (2011). Children's subjective well-being: international comparative perspectives. Children and Youth Services Review, 33, 548556.

Brannick, M. T. (1995). Critical comments on applying covariance structure modeling. Journal of Organizational Behavior, 16, 201-213.

Bryant, F. B., \& Cvengros, J. A. (2004). Distinguishing hope and optimism: Two sides of a coin, or two separate coins? Journal of Social and Clinical Psychology, 23, 273-302.

Casas, F., Sarriera, J. C., Abs, D., Coenders, G., Saforcada, J. A. E \& Tonon, G. (2012). Subjective indicators of personal well-being among adolescents. Performance and results for different scales in Latin-language speaking countries: A contribution to the international debate. Child Indicators Research. doi:10.1007/ s12187-011-9119-1.

Cheung, G. W., \& Rensvold, R. B. (2002). Evaluating goodness-of-fit indexes for testing MI. Structural Equation Modeling, 9, 235-55.

Coleman, J. S. (1988). Social capital in the creation of human capital. American Journal of Sociology, 94, S95-120.

Dew-Reeves, S., Athay, M. M., \& Kelley, S. D. (2012). Validation and use of the children's hope scale-revised PTPB edition (CHS-PTPB): high initial youth hope and elevated baseline symptomatology predict poor treatment outcomes. Administration and Policy in Mental Health and Mental Health Services Research, 39(1-2), 60-70.

Gilman, R., Dooley, J., \& Florell, D. (2006). Relative levels of hope and their relationship with academic and psychological indicators among adolescents. Journal of Social and Clinical Psychology, 25, 166-178.

Hall, K., Woolard, I., Lake, L., \& Smith, C. (Eds.). (2012). South African child gauge 2012. Cape Town: Children's Institute, University of Cape Town.

Holleran, S. and Snyder, C.R. (1990). Discriminant and convergent validation of the Hope Scale. Unpublished manuscript. Lawrence: University of Kansas.

Isaacs, S. A., \& Savahl, S. (2014). A qualitative inquiry investigating adolescents' sense of hope within a context of violence in a disadvantaged community in Cape Town. Journal of Youth Studies, 17(2), 269- 278. 
Kazdin, A. E., Rodgers, A., \& Colbus, D. (1986). The hopelessness scale for children: psychometric characteristics and concurrent validity. Journal of Consulting and Clinical Psychology, 54, 241-245.

Krieger, N., Williams, D. R., \& Moss, H. W. (1997). Measuring social class in US public health research: concepts, methodologies, and guidelines. Annual Review of Public Health, 18, 341-78.

Kwan, S. S. M. (2010). Interrogating Bhope ${ }^{\wedge}-$ the pastoral theology of hope and positive psychology. International Journal of Practical Theology, 14, 47-67.

McNulty, J. K., \& Fincham, F. D. (2012). Beyond positive psychology: toward a contextual view of psychological processes and well-being. American Psychologist, 67, 101-110.

Meredith, W. (1993). Measurement invariance, factor analysis, and factorial invariance. Psychometrika, 58, 525-542.

Merkaš, M., \& Brajša-Žganec, A. (2011). Children with different levels of hope: Are there differences in their self-esteem, life satisfaction, social support, and family cohesion? Child Indicators Research, 4, 499-514. Pruyser, P. W. (1963). Phenomenology and dynamics of hoping. Journal for the Scientific Study of Religion, 3, 86-96.

Pulido-Martos, M., Jiménez-Moral, J. A., Lopez-Zafra, E., \& Ruiz, J. R. (2014). An adaptation of the children's hope scale in a sample of Spanish adolescents. Child Indicators Research, 7(2), 267-278.

Rees, G., Pople, L., \& Goswami, H. D2011]. Understanding children's well-being: links between family economic factors and children's subjective well-being-initial findings from wave 2 and wave 3 quarterly surveys. London: The Children's Society. http://www.childrenssociety.org.uk/sites/default/files/tcs/ research_docs/Economic\%20Factors\%20March\%202011.pdf.

Savahl, S., Isaacs, S., Adams, S., Carels, C., \& September, R. (2013). An exploration into the impact of exposure to community violence and hope on children's perceptions of wellbeing: a South African perspective. Child Indicators Research, 6(3), 579-592.

Sawyer, W., Singh, M., Woodrow, C., Downes, T., Johnston, C., \& Whitton, D. (2007). Robust hope and teacher education policy. Asia-Pacific Journal of Teacher Education, 35(3), 227-242.

Seligman, M. E. P., \& Csikszentmihalyi, M. (2000). Positive psychology: an introduction. American Psychologist, 55(1), 5-14.

Singh, M., \& Sawyer, W. (2008). Democracy and robust hope: Queensland's education and training reforms for the future. Education, Citizenship and Social Justice, 3(3), 223237.

Snyder, C. R., Harris, C., Anderson, J. R., Holleran, S. A., Irving, L. M., et al. (1991). The will and the ways: development and validation of an individual-differences measure of hope. Journal of Personality and Social Psychology, 60, 570-585.

Snyder, C. R., Hoza, B., Pelham, W. E., Rapoff, M., Ware, L., Danovsky, M., et al. (1997). The development and validation of the children's hope scale. Journal of Pediatric Psychology, 22, 399-421.

Snyder, C. R., Shorey, H. S., Cheavens, J., Pulvers, K. M., Adams, V. H., \& Wiklund, C. (2002). Hope and academic success in college. Journal of Educational Psychology, 94(4), 820826. 
Snyder, C. R., Lopez, S. J., Shorey, H. S., Rand, K. L., \& Feldman, D. B. (2003). Hope theory, measurements, and applications to school psychology. School Psychology Quarterly, 18, 122-139.

Snyder, C. R., Rand, K. L., \& Sigmon, D. R. (2005). Hope theory: a member of the positive psychology family. In C. R. Snyder \& S. J. Lopez (Eds.), Handbook of positive psychology (pp. 257-267). New York: Oxford University Press.

Stats, S. A. (2008). Income and expenditure of households 2005/2006: analysis of results. Pretoria: Statistics South Africa.

Valle, M. F., Huebner, E. S., \& Suldo, S. M. (2004). Further evaluation of the children's hope scale. Journal of Psychoeducational Assessment, 22, 320-337.

Valle, M. F., Huebner, E. S., \& Suldo, S. M. (2006). An analysis of hope as a psychological strength. Journal of School Psychology, 44, 393-406. 